\title{
Tri-Band Fractal Antennas for RFID Applications
}

\author{
Abdelati Reha', Ahmed Oulad Said ${ }^{2}$ \\ ${ }^{1}$ Department of Telecommunications Engineering, Higher Institute of Applied Engineering (IGA), Marrakesh, Morocco; ${ }^{2}$ Depart- \\ ment of Electrical and Telecommunications Engineering, Royal Air Academy (ERA), Marrakesh, Morocco. \\ Email: reha.abdelati@gmail.com, a_ouladsaid@hotmail.com
}

Received July $5^{\text {th }}, 2013$; revised August $9^{\text {th }}, 2013$; accepted August $27^{\text {th }}, 2013$

Copyright (C) 2013 Abdelati Reha, Ahmed Oulad Said. This is an open access article distributed under the Creative Commons Attribution License, which permits unrestricted use, distribution, and reproduction in any medium, provided the original work is properly cited.

\begin{abstract}
The RFID is a rapidly developing technology. It's used in many applications such as logistics, ticketing, security, employee attendance record and others. Also, fractal technology is used in many areas, and recently in antenna design because it allows making multi-band and wide-band antennas. In this paper, two tri-band fractal antennas are studied for the Radio Frequency Identification (RFID) applications using the Method of Moment (MoM). The first one is designed for the RFID readers and it operates at 3.85 GHZ, 5.80 GHZ and 8.12 GHZ. The second one is designed for the RFID Tags and it operates at 3.94 GHZ, 5.65 GHZ and 8.20 GHZ.
\end{abstract}

Keywords: Antenna; Fractals; RFID (Radio Frequency Identification); Multi-Band; Wide-Band

\section{Introduction}

RFID stands for Radio Frequency Identification, a term that describes any system of identification wherein an electronic device that uses radio frequency or magnetic field variations to communicate is attached to an item. The two most talked-about components of an RFID system are the tag, which is the identification device attached to the item we want to track, and the reader, which is a device that can recognize the presence of RFID tags and read the information stored on them. The reader can then inform another system about the presence of the tagged items. The system with which the reader communicates usually runs software that stands between readers and applications. This software is called RFID middleware [1].

In a typical RFID system [2], passive tags are attached to an object such as goods, vehicles, humans, animals, and shipments, while a vertical/circular polarization antenna is connected to the RFID reader. The RFID reader and tag can radio-communicate with each other using a number of different frequencies, and currently most RFID systems use unlicensed spectrum. The common frequencies used are low frequency $(125 \mathrm{KHz})$, high frequency $(13.56 \mathrm{MHz})$, ultra high frequency $(860-960$ $\mathrm{MHz} / 2.45 \mathrm{GHz})$, and microwave frequency (3.6/3.9/5.8/ 5.9/8.2 GHZ [3]). The typical RFID readers are able to read (or detect) the tags of only a single frequency but multimode readers are becoming cheaper and popular which are capable of reading the tags of different frequencies [4].

Several calculation methods are adopted to solve the Maxwell equations and then study the performance of the antennas. Among these, two are widely used in simulation software:

1) The method of moments (MoM) is used among others in FEKO software (an abbreviation derived from the German phrase FEldberechnung bei Körpern mit beliebiger Oberfläche (Field computations involving bodies of arbitrary shape)) [5].

2) The method of finite integral (FIT) is used in the software CST Microwave Studio (Computer Simulation Technology Microwave Studio) [6].

In this work, we use the FEKO software.

\section{Fractal Antennas}

The fractal antennas use fractals and self-similar models. Several studies show that we can easily make compact, multi-band and wide-band antennas, suitable for miniaturization and various applications such as RFID, WLAN (Wireless Local Area Network), WIMAX (WorldWide Interoperability for Microwave Access), WIFI (WIreless FIdelity) [7-9]. 


\section{Antennas Geometry}

\subsection{Readers Antennas}

The reader antenna is a fractal antenna $2^{\text {nd }}$ iteration (Figure 1).

The antenna is fed by a Coplanar Waveguide (CPW). The antenna, the feeding point and the ground plane are on the same plane (Figure 2). Several studies have used this mode of feeding [10-13].

The antenna is designed on an FR4 substrate (relative dielectric constant $=4.3$, thickness $=1.6 \mathrm{~mm}$, loss tangent $=0.025)$. The overall dimension of the substrate is $40 \times 60 \mathrm{~mm}^{2}$.

The dimensions of the antenna are: $\mathrm{L}_{1}=60 \mathrm{~mm}, \mathrm{~L}_{2}=$ $40 \mathrm{~mm}, \mathrm{~L}_{3}=22 \mathrm{~mm}, \mathrm{H}=1.6 \mathrm{~mm}, \mathrm{H}_{1}=23 \mathrm{~mm}, \mathrm{H}_{2}=21$ $\mathrm{mm}, \mathrm{H}_{3}=10 \mathrm{~mm}, \mathrm{~W}=2.2 \mathrm{~mm}, \mathrm{~S}=1 \mathrm{~mm}, \mathrm{G}=0.5 \mathrm{~mm}$, $\theta=20^{\circ}, \alpha=40^{\circ}$ (Figure 3).

\subsection{Tag Antenna}

The Tag antenna is a fractal antenna $3^{\text {rd }}$ iteration (Figure 4).

The antenna is fed by a Coplanar Waveguide (CPW). The antenna, the feeding point and the ground plane are on the same plane (Figure 5).

The antenna is designed on an FR4 substrate (relative dielectric constant $=4.3$, thickness $=1.6 \mathrm{~mm}$, loss tangent $=0.025)$. The overall dimension of the substrate is $30 \times 90 \mathrm{~mm}^{2}$.

The dimensions of the antenna are: $\mathrm{L}_{1}=90 \mathrm{~mm}, \mathrm{~L}_{2}=$ $30 \mathrm{~mm}, \mathrm{~L}_{3}=10 \mathrm{~mm}, \mathrm{H}=1.6 \mathrm{~mm}, \mathrm{~W}=2.4 \mathrm{~mm}, \mathrm{~S}=1$ $\mathrm{mm}, \mathrm{G}=1 \mathrm{~mm}$ (Figure 6).

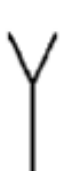

Iteration $\mathrm{N}^{\circ}$ :

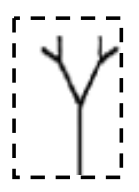

2

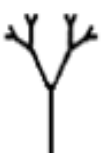

3

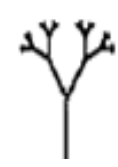

4
Figure 1. The first 4 iterations of the Tree-Fractal antenna.

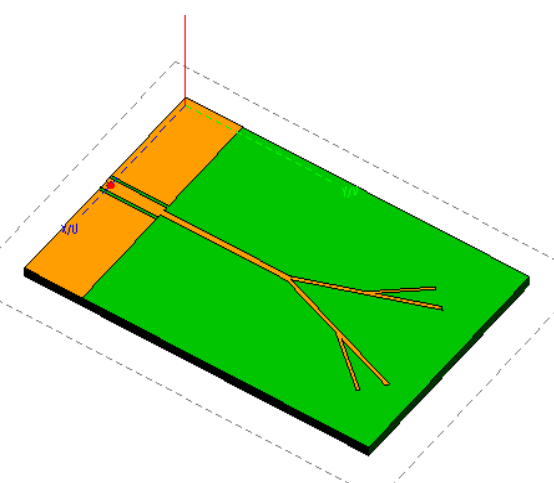

Figure 2. The Reader antenna fed by a coplanar waveguide (CPW).

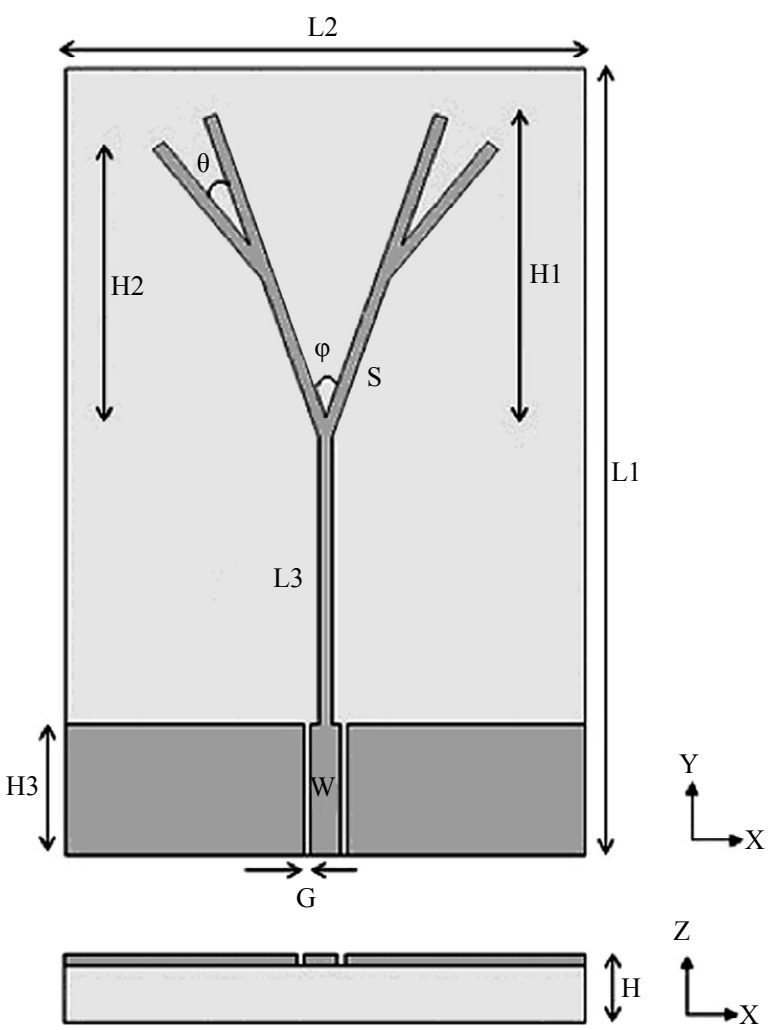

Figure 3. Dimensions of the Reader Antenna [3].

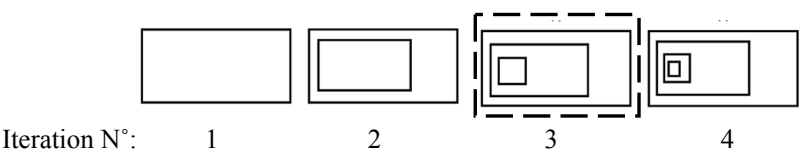

Figure 4. The first 4 iterations of the Rectangular-Fractal antenna.

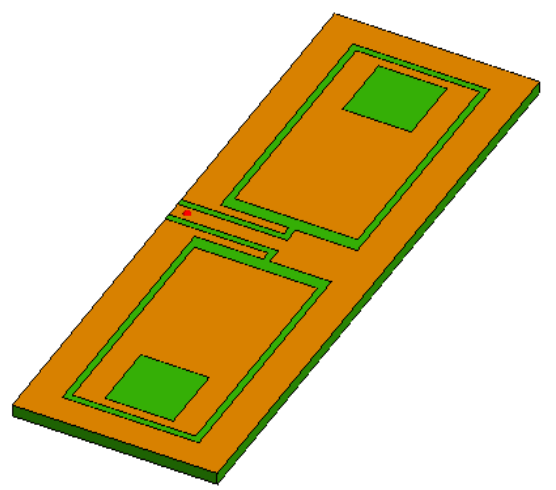

Figure 5. The Tag antenna fed by a coplanar waveguide (CPW).

\section{Results and Discussions}

\subsection{Reader Antenna}

The analysis of the $S_{11}$ parameter (Figure 7) shows that the Reader antenna operates at $\mathrm{f}_{1}=3.85 \mathrm{GHZ}, \mathrm{f}_{2}=5.8$ $\mathrm{GHZ}$ and $\mathrm{f}_{3}=8.12 \mathrm{GHZ}$. 


\section{$\underline{\mathrm{F}}_{1}=3.85 \mathrm{GHZ}$}

Around this frequency, the $S_{11}$ parameter shown by Figure 8, we note that the bandwidth is $305 \mathrm{MHZ}$ (from $3.69 \mathrm{GHz}$ to $4 \mathrm{GHZ}$ ).

We also note that the gain of this antenna is $2.6 \mathrm{dBi}$ for $\varphi=90^{\circ}$ and $\varphi=60^{\circ}$ as shown by Figure 9 .

$\underline{\mathbf{F}}_{2}=5.8 \mathrm{GHZ}$

Around this frequency, the $S_{11}$ parameter shown by Figure 10, we note that the bandwidth is $201 \mathrm{MHZ}$ (from $5.743 \mathrm{GHZ}$ to $5.944 \mathrm{GHZ}$ )

We also note that the gain of this antenna is $1.7 \mathrm{dBi}$ for $\varphi=90^{\circ}$ and $\varphi=270^{\circ}$ as shown by Figure 11.

\section{$\underline{\mathbf{F}}_{3}=8.12 \mathrm{GHZ}$}

Around this frequency, the $S_{11}$ parameter shown by Figure 12, we note that the bandwidth is $289 \mathrm{MHZ}$ (from

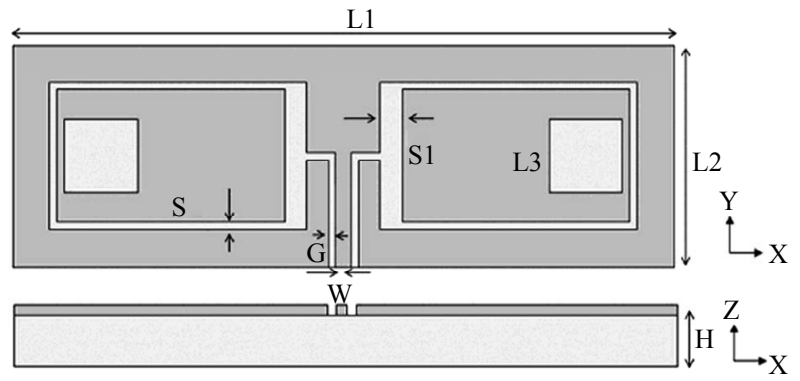

Figure 6. Dimensions of the Tag Antenna [3].

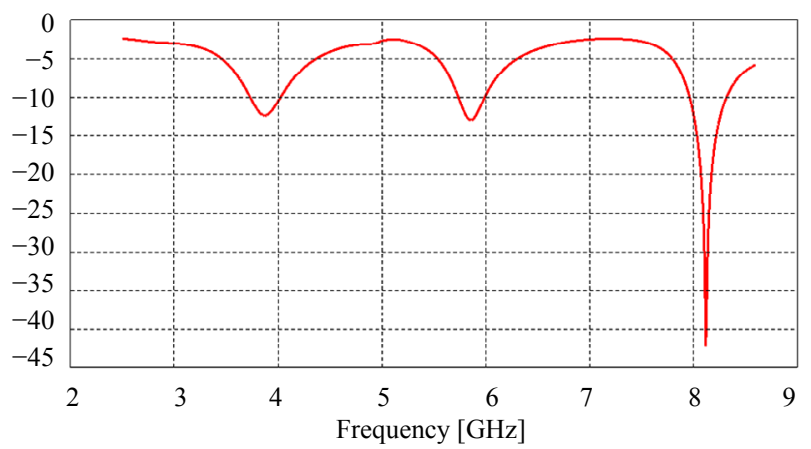

Figure 7. Simulated $S_{11}$ versus frequency graph of the Reader antenna.

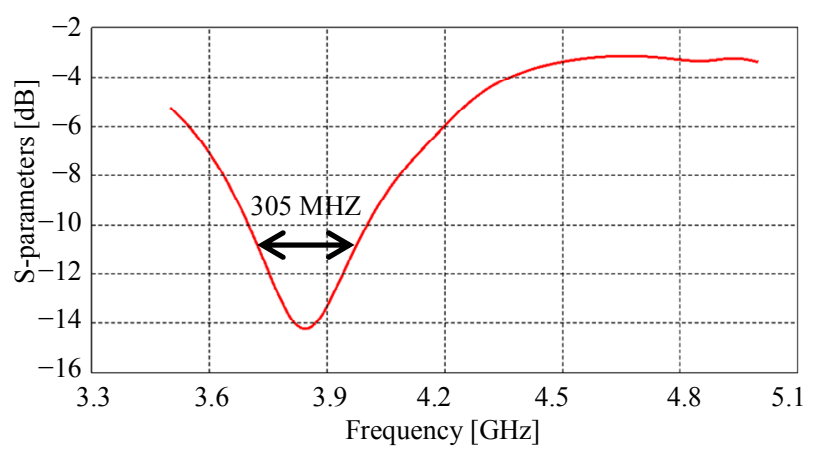

Figure 8. Evolution of $S_{11}$ around the frequency $f_{1}=3.85$ GHZ.

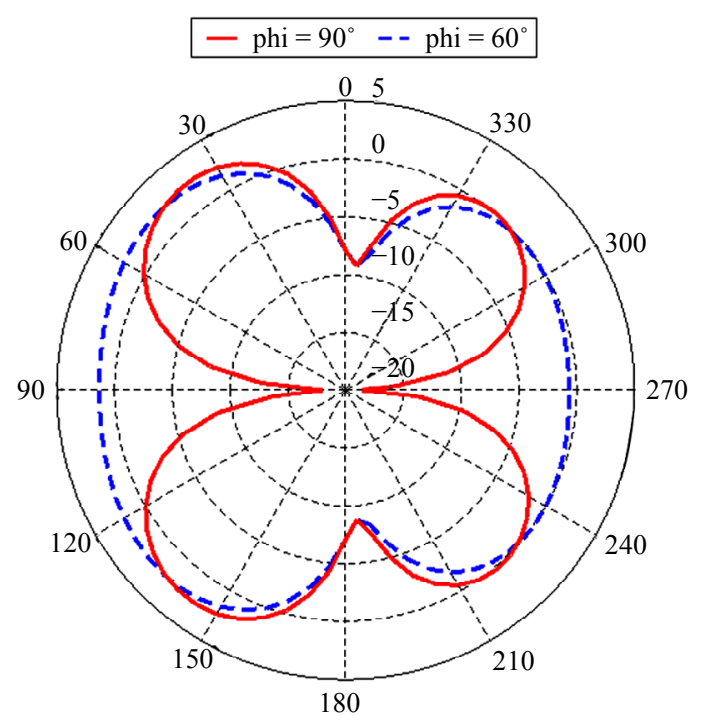

Figure 9. The gain of the antenna for $f_{1}=3.85 \mathrm{GHZ}$ (for $\varphi=$ $90^{\circ}$ and $\left.\varphi=60^{\circ}\right)-\mathrm{G}_{\max }=2.6 \mathrm{dBi}$.

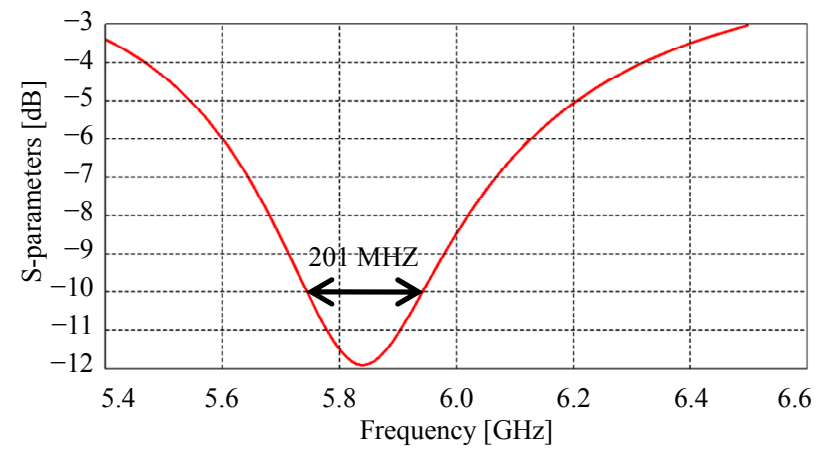

Figure 10. Evolution of $S_{11}$ around the frequency $f_{2}=5.8$ GHZ.

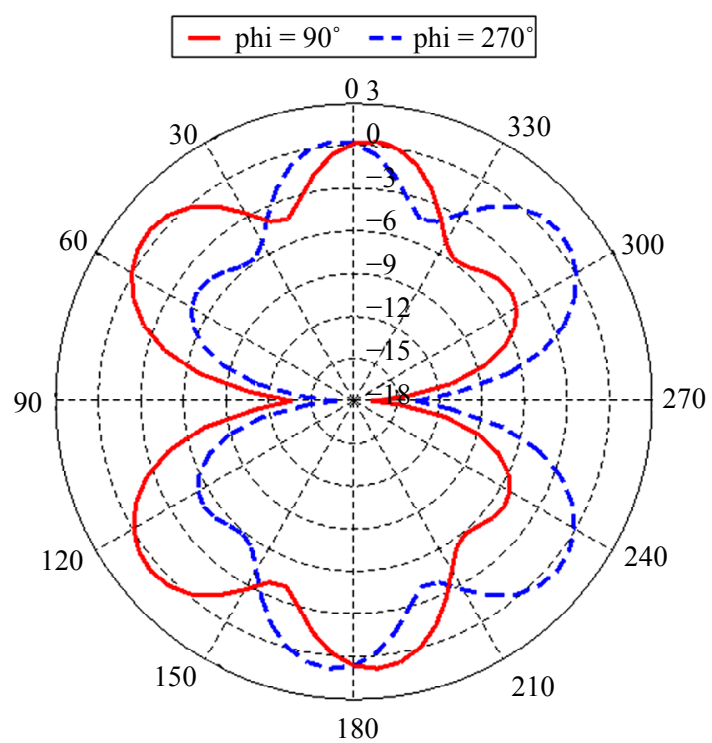

Figure 11. The gain of the antenna for $\mathrm{f}_{2}=5.8 \mathrm{GHZ}$ (for $\varphi=$ $90^{\circ}$ and $\left.\varphi=270^{\circ}\right)-\mathrm{G}_{\max }=1.7 \mathrm{dBi}$. 
7.989 GHZ to $8.278 \mathrm{GHZ}$ ).

We also note that the gain of this antenna is $2.7 \mathrm{dBi}$ for $\varphi=30^{\circ}$ and $\varphi=90^{\circ}$ as shown by Figure 13.

\subsection{Tag Antenna}

The analysis of the $S_{11}$ parameter (Figure 14) shows that the Tag antenna operates at $f_{1}=3.94 \mathrm{GHZ}, \mathrm{f}_{2}=5.65$

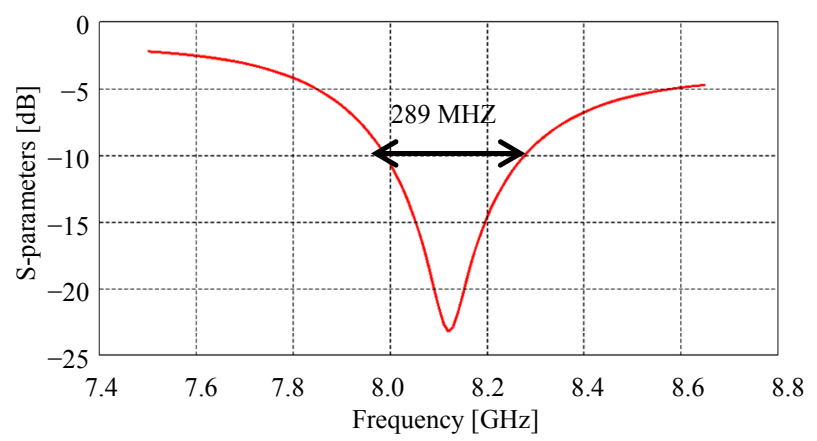

Figure 12. Evolution of $S_{11}$ around the frequency $f_{3}=8.12$ GHZ.

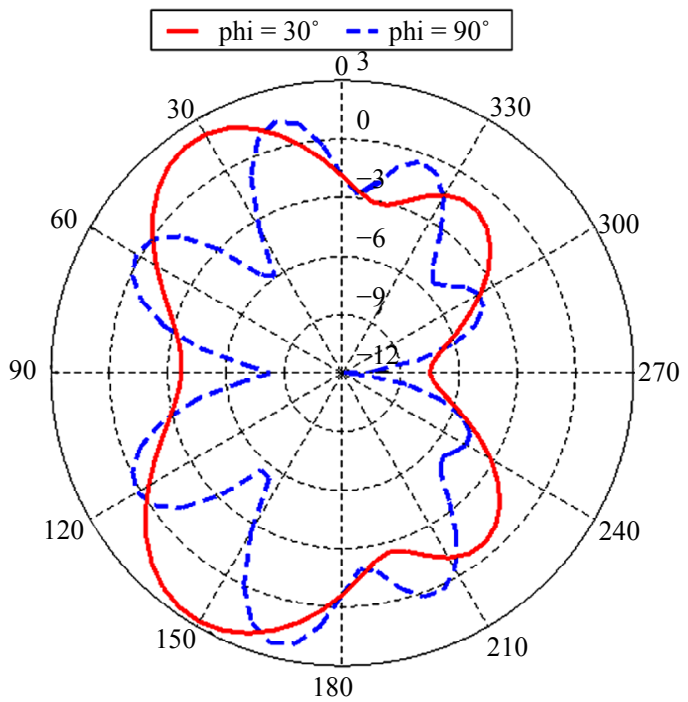

Figure 13. The gain of the antenna for $f_{3}=8.12 \mathrm{GHZ}$ (for $\varphi$ $=30^{\circ}$ and $\varphi=90^{\circ}$ ) $-\mathrm{G}_{\max }=2.7 \mathrm{dBi}$.

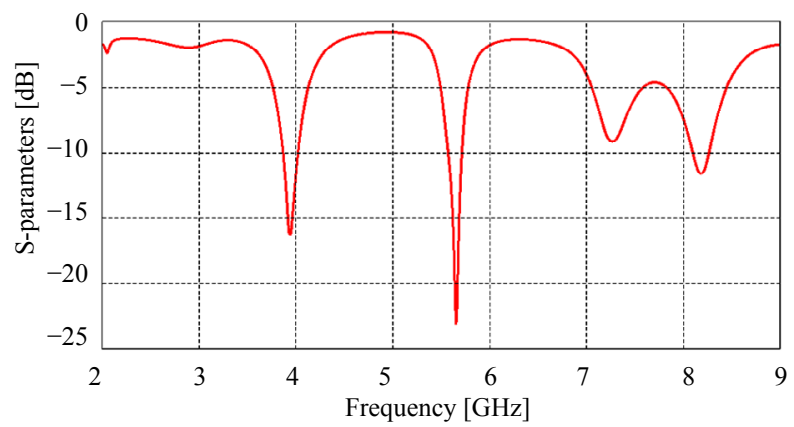

Figure 14. Simulated $S_{11}$ versus frequency graph of the Tag antenna.
$\mathrm{GHZ}$ and $\mathrm{f}_{3}=8.2 \mathrm{GHZ}$.

\section{$\underline{F}_{1}=3.94 \mathrm{GHZ}$}

Around this frequency, the $S_{11}$ parameter shown by Figure 15, we note that the bandwidth is $165 \mathrm{MHZ}$ (from $3.869 \mathrm{GHZ}$ to $4.0348 \mathrm{GHZ}$ ).

We also note that the gain of this antenna is $3.8 \mathrm{dBi}$ for $\varphi=0^{\circ}$ and $\varphi=180^{\circ}$ as shown by Figure 16.

\section{$\mathrm{F}_{2}=5.65 \mathrm{GHZ}$}

Around this frequency, the $S_{11}$ parameter shown by

Figure 17, we note that the bandwidth is $149 \mathrm{MHZ}$ (from 5.564 GHZ to 5.713 GHZ).

We also note that the gain of this antenna is $1.25 \mathrm{dBi}$ for $\varphi=0^{\circ}$ and $\varphi=180^{\circ}$ as shown by Figure 18 .

\section{$\underline{\mathbf{F}}_{3}=8.2 \mathrm{GHZ}$}

Around this frequency, the $\mathrm{S}_{11}$ parameter shown by Figure 19, we note that the bandwidth is $166 \mathrm{MHZ}$ (from 8.101 GHZ to 8.267 GHZ).

We also note that the gain of this antenna is $2.65 \mathrm{dBi}$ for $\varphi=0^{\circ}$ as shown by Figure 20.

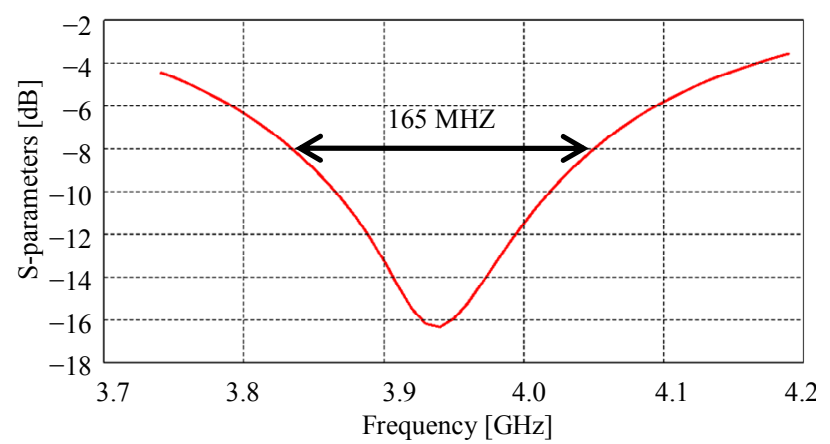

Figure 15. Evolution of $S_{11}$ around the frequency $f_{1}=3.94$ GHZ.

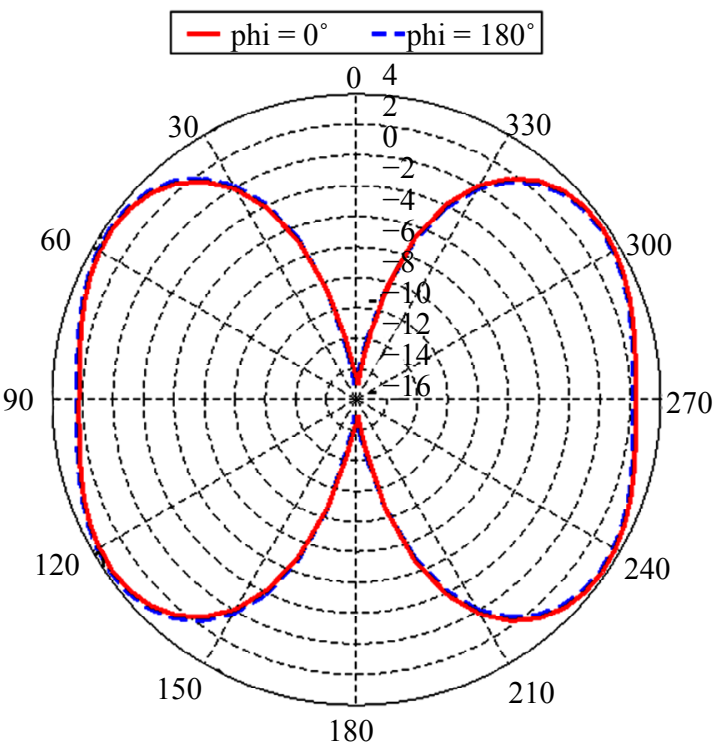

Figure 16. The gain of the antenna for $f_{1}=3.94 \mathrm{GHZ}$ (for $\varphi$ $=0^{\circ}$ and $\varphi=180^{\circ}$ ) $-\mathrm{G}_{\max }=3.8 \mathrm{dBi}$. 


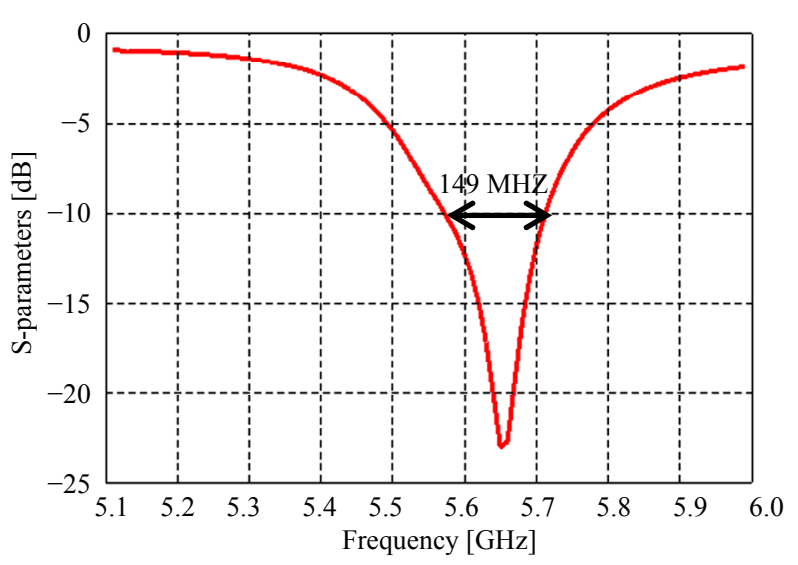

Figure 17. Evolution of $S_{11}$ around the frequency $f_{2}=5.65$ GHZ.

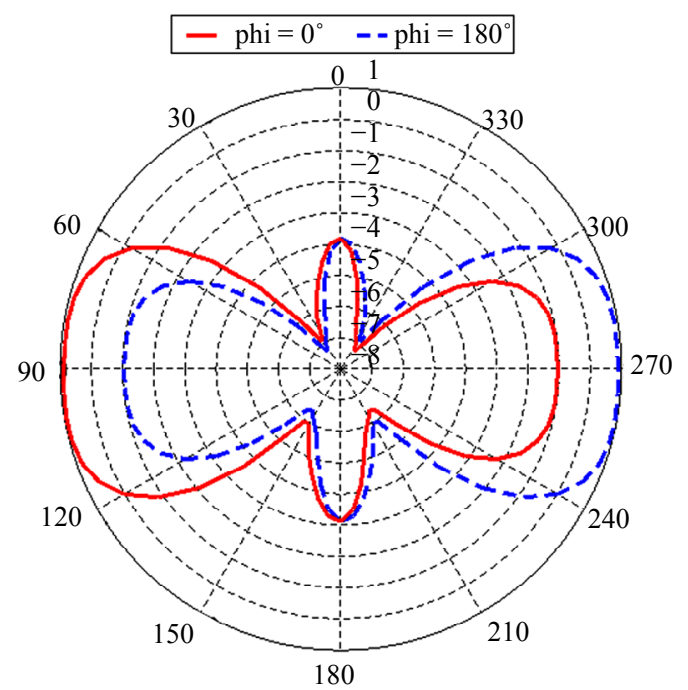

Figure 18. The gain of the antenna for $f_{2}=5.65 \mathrm{GHZ}$ (for $\varphi$ $=0^{\circ}$ and $\left.\varphi=180^{\circ}\right)-\mathrm{G}_{\max }=1.25 \mathrm{dBi}$.

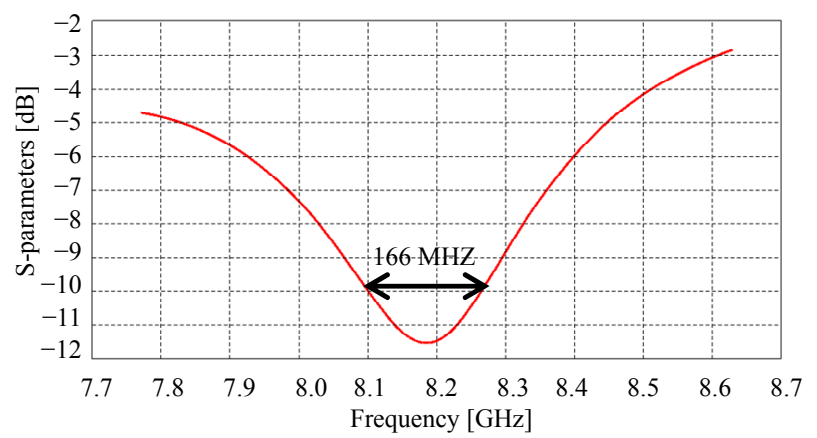

Figure 19. Evolution of $S_{11}$ around the frequency $f_{3}=8.2$ GHZ.

\section{Read Range of the Antennas}

To calculate the read range of these antennas, we apply the First Transmission Equation (EQ1) which gives the relationship between the received power $(\operatorname{Pr})$ as a func-

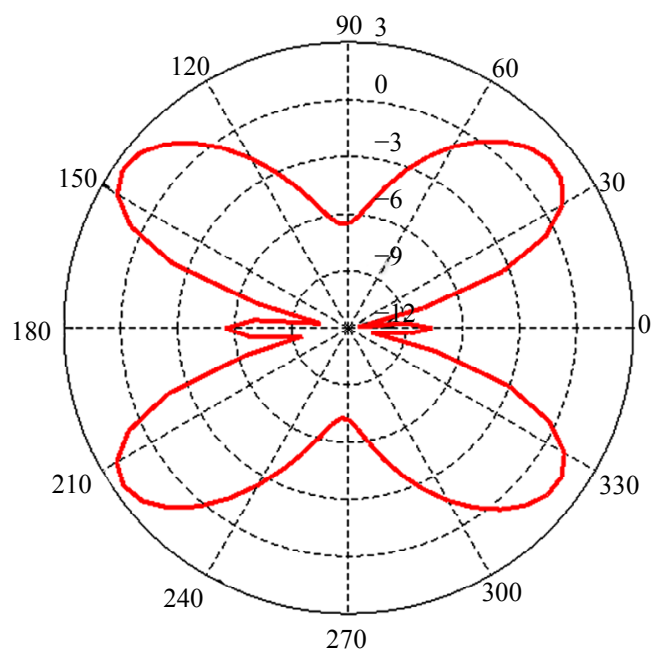

Figure 20. The gain of the antenna for $f_{3}=8.2 \mathrm{GHZ}$ (for $\varphi=$ $\left.0^{\circ}\right)-\mathrm{G}_{\max }=2.65 \mathrm{dBi}$.

tion of the transmitted power $(\mathrm{Pt})$, the antennas gain $(\mathrm{Gt}$, Gr) and free space loss which can be expressed in terms of the wavelength $(\lambda)$ and the distance between the antennas(R) .

$$
\begin{aligned}
& \frac{P_{r}}{P_{t}}=G_{t} \cdot G_{r}\left(\frac{\lambda}{4 \cdot \pi \cdot R}\right)^{2} \\
& R=\frac{c}{4 \cdot \pi \cdot f} \cdot \sqrt{\frac{P_{t} \cdot G_{t} \cdot G_{r}}{P_{r}}} \\
& \lambda=\frac{c}{f}
\end{aligned}
$$

For each one of the antennas, the read range calculation is done by taking a reference antenna of gain $3 \mathrm{dBi}$ and minimum detectable power of $1 \mathrm{~mW}$. The transmitting power is $4 \mathrm{~W}$ [3]. Therefore, we can build the table below (Table 1).

\section{Comparison with other Methods of Calculation}

This study has been done with The CST Microwave Studio which is based on the finite integral method (FIT) [3]. Our results are similar, but with small differences summarized in the Table 2 .

Comparing these results, we note that:

- For the Reader, there is a small frequency lag of 0.25 $\mathrm{GHZ}\left(\mathrm{f}_{1 \text { FIT }}=3.6 \mathrm{GHZ}\right.$ and $\left.\mathrm{f}_{1 \mathrm{MoM}}=3.85 \mathrm{GHZ}\right)$

- For the Tag, there is a small frequency lag of 0.25 $\mathrm{GHZ}\left(\mathrm{f}_{2 \text { FIT }}=5.9 \mathrm{GHZ}\right.$ and $\left.\mathrm{f}_{1 \mathrm{MoM}}=5.65 \mathrm{GHZ}\right)$

\section{Conclusions}

The fractal antennas are preferred due to small size, light weight and multiband. This paper introduced RFID reader and tag antennas. The reader antenna exhibits a -10 $\mathrm{dB}$ bandwidth of $305 \mathrm{MHz}$ at $3.85 \mathrm{GHz}, 201 \mathrm{MHz}$ at 5.8 
Table 1. Read range antennas.

\begin{tabular}{cccc}
\hline $\begin{array}{c}\text { frequency } \\
(\mathrm{GHZ})\end{array}$ & Antenna type & $\begin{array}{c}\text { Gain of the } \\
\text { antenna (dBi) }\end{array}$ & Read range (cm) \\
\hline 3.85 & Reader & 2.6 & 74.72 \\
3.94 & Tag & 3.8 & 83.83 \\
5.8 & Reader & 1.7 & 44.72 \\
5.65 & Tag & 1.25 & 43.59 \\
8.12 & Reader & 2.7 & 35.84 \\
8.2 & Tag & 2.65 & 35.28 \\
\hline
\end{tabular}

Table 2. Comparison of results between the two methods MoM and FIT.

\begin{tabular}{cccc}
\hline $\begin{array}{c}\text { frequency } \\
(\mathrm{GHZ})\end{array}$ & $\begin{array}{c}\text { Calculation Method } \\
\text { (Simulation software) }\end{array}$ & $\begin{array}{c}\text { Gain of the } \\
\text { antenna }(\mathrm{dBi})\end{array}$ & $\begin{array}{c}\text { Read range } \\
(\mathrm{cm})\end{array}$ \\
\hline \multicolumn{4}{c}{ READER ANTENNA } \\
$\mathbf{3 . 6}$ & FIT (CST) & 3.4 & 87.50 \\
$\mathbf{3 . 8 5}$ & MoM (FEKO) & 2.6 & 74.72 \\
5.8 & FIT (CST) & 2.7 & 50.10 \\
5.8 & MoM (FEKO) & 1.7 & 44.72 \\
8.2 & FIT (CST) & 2.6 & 35.06 \\
8.10 & MoM (FEKO) & 2.7 & 35.84 \\
& TAG ANTENNA & \\
3.9 & FIT (CST) & 3.9 & 85.60 \\
3.94 & MoM (FEKO) & 3.8 & 83.83 \\
$\mathbf{5 . 9}$ & FIT (CST) & 3.0 & 51.02 \\
$\mathbf{5 . 6 5}$ & MoM (FEKO) & 1.25 & 43.59 \\
8.2 & FIT (CST) & 2.2 & 33.48 \\
8.2 & MoM (FEKO) & 2.65 & 35.28 \\
\hline
\end{tabular}

$\mathrm{GHz}$, and $289 \mathrm{MHz}$ at $8.12 \mathrm{GHz}$. The tag antenna exhibits a $-10 \mathrm{~dB}$ bandwidth of $165 \mathrm{MHz}$ at $3.94 \mathrm{GHz}, 149$ $\mathrm{MHz}$ at $5.65 \mathrm{GHz}$, and $166 \mathrm{MHz}$ at $8.2 \mathrm{GHz}$. The maximum read range obtained by the reader antenna is 74.72 $\mathrm{cm}$, and $83.83 \mathrm{~cm}$ by the tag antenna.

By simulating the antennas using the Method of Moment (MoM) and comparing the results with another study using the method of finite integral (FIT), we find that the results are similar, even if there are small lags that are tolerable.

\section{REFERENCES}

[1] H. Bhatt and B. Glover, "RFID Essentials," O'Reilly, Se- bastopol, 2006.

[2] S. B. Miles, S. E. Sharma and J. R. Williams, "RFID Technology \& Applications," Cambridge University Press, New York, 2011.

[3] C. Varadhan, J. K. Pakkathillam, M. Kanagasabai, R. Sivasamy, R. Natarajan and S. K. Palaniswamy, "Triband Antenna Structures for RFID Systems Deploying Fractal Geometry," IEEE Antennas and Wireless Propagation Letters, Vol. 12, 2013, pp. 437-440. http://dx.doi.org/10.1109/LAWP.2013.2254458

[4] G. O. Young, "Synthetic Structure of Industrial Plastics (Book Style with Paper Title and Editor)," In: J. Peters, Ed., Plastics, McGraw-Hill, New York, 1964, pp. 15-64.

[5] "FEKO 5.5 User's Manual," EM Software \& Systems-S. A, 2009, pp. 1-1.

[6] B. Bieda and P. Słobodzian, "Efficiency of the IE-MoM Approach in the Analysis of Dielectric Bodies Embedded in a Cavity," 2010 18th International Conference on Microwave Radar and Wireless Communications (MIKON), Vilnius, 14-16 June 2010, pp. 1-4.

[7] A. Mehdipour, L. Rosca, A. Sabek, C. Trueman and S. Hoa, "Full Composite Fractal Antenna Using Carbon Nanotubes for Multiband Wireless Applications," IEEE Antennas Wireless Propagation Letters, Vol. 9, 2010, pp.891895. http://dx.doi.org/10.1109/LAWP.2010.2076342

[8] A. Ismahayati, P. J. Soh and R. Hadibah, "Design and Analysis of a Multiband Koch Fractal Monopole Antenna," 2011 IEEE International RF and Microwave Conference (RFM), Seremban, 12-14 December 2011, pp. 58-62.

[9] D. H. Werner and S. Ganguly, "An Overview of Fractal Antenna Engineering Research," IEEE Antennas and Propagation Magazine, Vol. 45, No. 1, 2003, pp. 38-57.

[10] A. Mak, C. R. Rowell, R. D. Murch and M. Chi-Lun, "Compact Multiband Planar Antenna for 2.4/3.5/5.2/5.8$\mathrm{GHz}$ Wireless Applications," IEEE Antennas Wireless Propagation Letters, Vol. 11, 2012, pp. 144-147. http://dx.doi.org/10.1109/LAWP.2012.2185915

[11] D. C. Chang, B. H. Zeng and J. Liu, "CPW-Fed Circular Fractal Slot Antenna Design for Dual-Band Applications," IEEE Transactions on Antennas and Propagation, Vol. 56, No. 12, 2008, pp. 3630-3637. http://dx.doi.org/10.1109/TAP.2008.2007279

[12] J. H. Gu, S. S. Zhong, L. L. Xue and Z. Sun "Dual-Band Monopole Antenna for 2.45/5.8 GHz RFID Applications," 2008 China-Japan Joint Microwave Conference, Shanghai, 10-12 September 2008, pp. 133-135.

[13] B. D. Bala, M. K. A. Rahim, N. A. Murad, M. F. Ismail and H. A. Majid, "Design and Analysis of Metamaterial Antenna Using Triangular Resonator," 2012 Asia-Pacific Microwave Conference Proceedings (APMC), Kaohsiung, 4-7 December 2012, pp. 577-579. 